\title{
Formation of an Environmental Monitoring System as a Tool for Managing the State of Water Bodies
}

\author{
Rustam Gakaev*
}

\author{
Chechen State University named after A.A. Kadyrova, Grozny, Russian Federation \\ ${ }^{*}$ Corresponding author.Email: rustam.geofak@yandex.ru
}

\begin{abstract}
In recent decades, there has been an increase in anthropogenic impact on the environment due to the large-scale human impact on the biosphere. The priority directions of activity of the state and society are preservation of the environment and improvement of its quality. Environmental protection measures will lead to the desired results when implementing the principle of reliability and relevance of available information about the natural state of both its individual components and the biosphere as a whole. Natural monitoring copes with this task. The most important result of this process - environmental monitoring - is a variety of information about pollution sources, about the current and future state of the biosphere, the concentration of all pollutants in various biological environments.
\end{abstract}

Keywords: anthropogenic impact on the environment, biosphere, preservation of the environment, natural monitoring, sources of pollution.

\section{INTRODUCTION}

The process of monitoring the habitat is, first of all, tracking the state of the natural environment, as well as its individual components (such as flora, fauna, soil, water, air and other components), the second role of minimonitoring is to prevent all emerging bio-critical situations, for example, a sharp increase in the concentration of pollutants in the atmosphere. This method of observation (or monitoring) has been used since ancient times in all practical and scientific activities. This method is a method of cognition, which is based on long-term and purposeful tracking of objects of interest and environmental phenomena. Let's turn to the origins of this phenomenon. In the 1 st century BC. Gaya Pliny, in his treatise Natural History, described his first observations of the natural environment. His work was the most complete encyclopedia in the fields of medicine, history, agriculture, botany, geography, physics, and astronomy. All this information was contained in 37 volumes and was the most complete encyclopedia of that time [1].

There are rumors about "green" technologies, this direction seems distant, but despite this, global warming is currently on a huge scale. Progressive and modern combustion systems and new energy sources, the energy crisis is gaining momentum - all of the above affects anthropogenic pollution of the environment. New management skills are being developed to manage resources in industry, but vast natural resources such as the Yamuna mineral water are not available.

Alternative technologies that can create jobs that are environmentally friendly and sustainable while helping space exploration and solving most of the above problems have been discussed in light of ancient Sanskrit science and technology literature. But it is for these phenomena that people adhere to human and professional ethics. Consider current trends and issues that are important and of concern to current trends. First, efficient thermal power plants, two- and four-stroke engines. The current trend is to create environmentally friendly thermal power plants using tons of coal and fuel oil. There is also a trend towards the creation of efficient twostroke and four-stroke engines used in motorcycles, cars, trucks, etc. in order to reduce the anthropogenic load on the environment. Research is focused on the use of biofuels or hydrogen. The problem is that despite all the measures taken, global warming is growing exponentially. What is the reason? This is probably not the case. There are four main reasons. First, it is the release of the Amedhya substance into the atmosphere. What is this "Amedhya"? This is practically such a substance, when released into the atmosphere, even in parts per million or billions of parts, it will have a huge impact on the atmosphere. This phenomenon has a tremendous impact on the environment. 


\subsection{Territorial Levels of Habitat Monitoring}

There is some seeding effect in the destruction of the ozone layer or electromagnetic fields that protect our atmosphere from external bombardment by hazardous substances or radiation. Burning fossil fuels completely or collecting carbon dioxide will not help if we do not capture the "Amedhya" contained in fossil fuels. These Amedhya substances are very difficult to trace. That is why nature has buried fossil fuels underneath so that over time their "amedhya" will disappear. How foolish of us to dig up the garbage and burn it. That is why Lord "Manu" clearly instructs: "Do not throw" Amedhya "into the fire?" [1]. Simple instruction, but very important. The second reason is the excessive use of oxygen. The amount of oxygen required to produce energy, even with the complete combustion of fossil fuels, biofuels or hydrogen, is enormous. How? Oxygen consumed when driving a car is $22.5 \mathrm{~kg} / \mathrm{h}$, which is 750 times more than the amount of oxygen needed by a person [2]. Now millions of cars and thousands of power plants burn millions of tons of fossil fuels. Will the ozone layer and oxygen in the atmosphere be affected? The third reason is the heat generated in the atmosphere. The efficiency of the modified Rankine cycle used in steam power plants is about $37 \%$ for the given temperatures and pressures [3]. If the efficiency of steam boilers is assumed to be 90 (on the upper side), the overall efficiency is about 33\%. There are similar figures for piston engines. This means that about $70 \%$ of the heat generated by burning fossil fuels is transferred to the atmosphere or water in the oceans. When counting numbers, this is an alarming amount. Nuclear power plants are no exception. As a result, global warming is inevitable. The fourth reason is vibrations emitted into the atmosphere. It's nice to hear the horse ride. Perfectly tuned classical music has a calming effect on body and mind. However, the shrill noise of the piston engine is definitely not to the liking. It is not displeasure that worries. The effect of this shrill noise on the atmosphere is worrying. The current trend is noise reduction. You have to be careful here. Proceedings of the National Conference on Trends and Advances in Mechanical Engineering, YMCA University of Science and Technology, Faridabad, Haryana, October 19-20, 2012840 What Can Be Heard by Human Ears. But once vibrations arise, whether they are audible or not, they have an immediate impact on the environment. Subtle vibrations, in addition to vibrations of a mass particle, also have an impact. A little meditation will clarify this. The huge electromagnetic waves created for mass telecommunications are also detrimental. This is well known.

\section{RESULTS AND DISCUSSION}

Groundwater monitoring is an observation structure that is used to analyze the current state of groundwater and the scenario of its change under the influence of man.
Groundwater samples are taken for research either from existing water supply wells used for domestic needs by adjacent residents, or from provided and drilled observation wells. Therefore, the groundwater monitoring network is a network of wells of different ages and types [6-7]. Groundwater monitoring is carried out in many ways and is divided into two types: systematic observations and specific observations, which provide scenarios for the development of mapping. Systematic observations are carried out to monitor the condition of water wells and determine the quality of water. These include determining the water level in the well, calculating water flow and determining the levels of water pollution in relation to normal indicators. In each well, more than 1 sample per year is taken separately to determine chemical indicators, which indicate an excessive amount of pollutants in the water, and at least 4 samples per year to assess microbiological indicators. Specific forecast studies will be carried out to improve the functioning of the water supply areas and to reevaluate the groundwater resources used in the water supply area. Equipment for monitoring groundwater indicators consists of a level gauge (for measuring the level of well water), a thermometer, Samplers (for taking water samples) and flow meters (for determining the flow rate of a well). Automatic data acquisition devices are usually used to collect and store set parameters.

Soil monitoring should only be done in warm and dry climates (summer, early fall). Field training on monitoring and monitoring of soil parameters, including monitoring, is usually carried out in winter [6] .:

- a complete study of the areas where monitoring is carried out. The main reason for the analysis is soil and geochemical maps that are scaled to the scale of the detailed topographic maps used for exploration;

- Collecting data on the sources of soil pollution in a given area (location, amount of waste, methods of disposal); - approving the timing of the control, determining the main sites where soil samples will be collected.

During the inspection of the soil, special sections and samples of the mixed soil may be taken. A sample from this area should be taken with a 100-150 g drill; a mixed sample should be taken in the following order: 5-15 samples from specific locations should be collected in a container, which should be thoroughly mixed, and a 500 g sample of the resulting mixture should be taken [7]. Therefore, soil monitoring in the territory covered by the project has its own characteristics: - In settlements, samples are taken according to a grid scheme, while 5-6 samples are taken per 100 hectares. Collect samples from a depth of $20 \mathrm{~cm}$.at Landfills for sampling are taken from a grid in squares with a step of $1 \mathrm{~km}$ at depths of 1-5, 5 $\mathrm{km} 0$ and $25 \mathrm{~cm}$. - in areas near large industrial enterprises, samples are taken from 4-8 wind directions to different distances from the enterprise (from $100 \mathrm{~m}$ to $15-20 \mathrm{~km}$ ). - along linear objects, soil samples are taken 
along paths parallel to the object at distances of 50, 100, 200 and 500 meters. Samples are taken from a $20 \mathrm{~cm}$ hole. - rural area: firstly, a plot of 100-200 $\mathrm{m} 2$ is limited by the area of this plot (garden, field, etc. in relation to a plot of 10-15 hectares. Inside all objects, samples are collected in a single grid with a step of 10 10-50 50 meters [8-9] Sampling depth: 2, 5, 10, 20, 40 special devices are used to monitor the soil: a drill (for collecting samples), a hydrometer (for studying the granulometric composition of the soil), a $\mathrm{pH}$ meter (for calculating soil acidity) and many express laboratories, where reagents are selected, which, as a rule, can be used to determine the degree of excessive soil contamination directly at the sampling site. Biological activity of soil (BAP) is determined in solid laboratories using microscopes [9] to determine species composition of microorganisms found in the sample. Environmental analysis provides a comprehensive analysis of all the potential advantages and disadvantages in the environmental, economic and social spheres associated with the economic development of the region [10]. This will allow the region to develop in a balanced and consistent manner, both in terms of socio-economic application, and in terms of environmental protection and improving the situation of its inhabitants. Currently, appraisal activities are developing mainly in two directions: environmental monitoring of projects and environmental assessment of residential areas.

An environmental forecast, based on data obtained from the study of materials collected during sampling from wells, is a scientific forecast of the state of the environment caused by human activities or the likely location of the ecosystem. Environmental forecast and assessment of the expected position of the biosphere is the final stage of river and river management [11]. There are rules for predicting the state of the environment, in accordance with which the spread of harmful substances and the regularities of the reaction of various organisms to changes in the environment. Environmental forecasts are supported by information about the state of the environment, both now and in recent days. Through longterm further research, we can demonstrate a desire to improve the environment in this area.

\section{CONCLUSION}

Control is the main component of environmental control, which is carried out by the state. The main task of monitoring is to monitor the state of the natural environment and the level of its pollution. It is also very important to timely determine the results of human impact on human life, ecosystems and human health, as well as the profitability of environmental protection measures. However, observation is not only a search and assessment of facts, but also an experimental reconstruction of the main components of the studied subject in order to develop scientific forecasts and proposals for resolving the situation in the natural environment. When developing a specific observation model, it is important to correctly prioritize which regions of the selected area belong to the observation network, detect natural elements and sources of pollution in real time, and what indicators are recorded during the study. At the regional level, the gap mainly extends to large industrial centers, water supplies and fish breeding grounds. In the context of the causes of environmental violations, priority is given to the causes that have the most stable and long-term impact on negative environmental changes. In terms of natural components, atmospheric air is mainly controlled and monitored (since its properties negatively affect all local residents) and fresh water (since it is mainly used as drinking water). As for the sources of pollution, when determining the tasks to be solved, priority is given to road transport, thermal power plants and non-ferrous metallurgy enterprises. Impurities (when monitoring atmospheric air indicators) - sulfur dioxide, carbon monoxide, nitrogen oxides, benzopyrene and dust; when monitoring indicators of surface water - oil products, phenol, biogenic products. It follows from this that for the development of a high-quality project, the following information is needed, obtained as a result of monitoring systems for the identified indicators [12]. 1. information on sources available in the region and information on emissions of pollutants into the environment: location and number of industrial enterprises, landfills, household waste and agricultural peat; information about man-made accidents and catastrophes. 2. information on the removal and transfer of pollutants outside the cultivated area and information on the transfer of pollutants through rivers and lakes, groundwater horizons and groundwater.

\section{ACKNOWLEDGMENTS}

The work was carried out within the framework of the state assignment of the Ministry of Science and Higher Education of the Russian Federation (topic No. 075-032021-074 / 4).

\section{REFERENCES}

[1] V.A. Bogoslovsky, A.D. Zhigalin, Ecological Geophysics 2018 p. 256.

[2] Yu.A. Izrael, Ecology and control of the state of the natural environment, 2019 p. 560.

[3] O. M. Mazur, Engineering Ecology 2020 p. 315.

[4] Ya.P. Molchanova, Hydrochemical indicators of the state of the environment, 2019 p. 192.

[5] O.F. Balatsky, L.G. Melnik, A.F. Yakovlev, Economics and Quality of the Environment 2019 p. 152. 
[6] I. A. Bayrakov, R. A. Gakaev, Geoecological bases of water resources use in the Chechen Republic, 2006 pp. 45-50.

[7] I.A. Bayrakov, R.A. Gakaev, Regional lake monitoring - the basis for studying the consequences of anthropogenic impacts on the lakes of the Chechen Republic, 2007 pp. 12-16.

[8] H. B Dulal, R. Dulal, P.K. Yadav, Delivering Green Economy in Asia: The Role of Fiscal Instruments. Futures 732019 pp. 61-77.

[9] J. Mauritzen, Contractors and Scale: An Empirical Analysis of the California Solar Market, 2016 pp. 105-214.

[10] J. Meckling, L. Hughes, Protecting Solar: Global Supply Chains and Business Power. New Political Economy 23(1) pp. 88-104.

[11] I. Monasterolo, M. Raberto, The EIRIN Flow-ofFunds Behavioural Model of Green Fiscal Policies and Green Sovereign Bonds. Ecological Economics 1442018 pp. 228-243. 